\title{
Ueber das Aethal.
}

Schon bei seiner früheren Arbeit über den Wallrath hatte W. Heintz nachgewiesen, dass das Aethal nicht eine einfache Base mit Hydratwasser sei, sondern aus wenigstens zwei Basen bestehe, welche zweite er Stethal nannte. Er kam zu dieser Entdeckung, weil durch die Einwirkung von Kali und Kalkhydrat auf das sogenannte Aethal unter Wasserstoffentwickelung sich Stearin- und Palmitinsäure bildete. Die Entdecknng von vier Säuren im Wallrath veranlasste die Vermuthung, dass auch die Alkohole der übrigen entsprechenden Säuren noch im Aethal enthalten sein müssten. W. Heintz stellte sich erst von allen Säuren freies Aethal durch tractionirte Zerlegung, durch wiederholtes Behandeln mit Weingeist und Umkrystallisiren dar und behandelte dies Aethal mit Kalikalk bei einer Temperatur von $275^{\circ}-280^{\circ} \mathrm{C}$., bis durchaus kein Wasserstoffgas mehr frei wurde, und überzeugte sich, indem er das so dargestellte Kalisalz mit Salzsäure zerlegte, dass die nun erhaltenen Säuren in ihren Gemischen auch Myristin- und Laurostearinsäure enthielten. Er gelangte hierdurch zu dem Schlusse, dass in dem früher unter dem Namen Aethal bekannten Körper vier verschiedene Körper zusammengefasst worden seien. Diese vier Substanzen sind unter der allgemeinen Formel zusammenzufassen $\mathrm{C}^{4 n} \mathrm{H}^{4 n}+2 \mathrm{O}^{2}(\mathrm{n}=$ ganze Zahl im Werth von $9,8,7,6$.) Von diesen Körpern waren zwei schon früher bekannt, das Aethal und Stethal, die beiden andern nennt er nach den Säuren, welche daraus hervorgehen, d. h. nach den Anfangsbuchstaben derselben, Methal und Lethal. Es verhalten sich diese Körper zu den Fettsäuren im Wallrath, wie der Alkohol zur Essigsäure. Diese Körper sind also:

$$
\begin{aligned}
& \text { Stethal }=\mathrm{C}^{36} \mathrm{H}^{38} \mathrm{O}^{2} \\
& \text { Aethal }=\mathrm{C}^{32} \mathrm{H}^{34} \mathrm{O}^{2} \\
& \text { Methal }=\mathrm{C}^{28} \mathrm{H}^{30} \mathrm{O}^{2} \\
& \text { Lethal }=\mathrm{C}^{24} \mathrm{H}^{26} \mathrm{O}^{2}
\end{aligned}
$$

Die Radicale dieser Oxydhydrate oder Alkohole würde man am besten Stethalyl $\mathrm{C}^{36} \mathrm{H}^{37}$, Aethalyl $\mathrm{C}^{32} \mathrm{H}^{33}$, Methalyl $\mathrm{C}^{28} \mathrm{H}^{29}$, Lethalyl $\mathrm{C}^{24} \mathrm{H}^{25}$ nennen. In dem Wallrath kann nun jede der darin enthaltenen vier Säuren im wasserfreien Zustande mit jedem der Oxyde dieser Radicale verbunden gedacht werden, wo wir dann sechszehn zusammengesetzte Aetherarten darin hätten. Es ist aber möglich und wohl auch wahrscheinlich, dass der 
Wallrath nur aus vier zusammengesetzten Aetherarten besteht, nämlich aus

Stearinsaurem Stetalyloxyd $=\mathrm{C}^{36} \mathrm{H}^{35} \mathrm{O}^{3}+\mathrm{C}^{36} \mathrm{H}^{37} \mathrm{O}$
Palmitinsaurem Aethalyloxyd $=\mathrm{C}^{32} \mathrm{H}^{31} \mathrm{O}^{3}+\mathrm{C}^{32} \mathrm{H}^{33} \mathrm{O}$
Myristinsaurem Methalyloxyd $=\mathrm{C}^{28} \mathrm{H}^{27} \mathrm{O}^{3}+\mathrm{C}^{28} \mathrm{H}^{29} \mathrm{O}$
Laurostearins. Lethalyloxyd $=\mathrm{C}^{24} \mathrm{H}^{23} \mathrm{O}^{3}+\mathrm{C}^{24} \mathrm{H}^{25} \mathrm{O}$.

Die aus der Behandlung des rohen Aethals mit Kalikalk erhaltenen Säuren erhielt W. Heintz nur in sehr geringer Menge und konnte dieselben nicht durch die vorhandenen physikalischen Eigenschaften oder gar durch die Elementaranalyse nachweisen. Fr bediente sich deshalb ihres Schmelzpunctes, und zwar desselben in Verbindung mit einer andern Säure. Er hält diese Art der Bestimmung boi einem Gemisch von zwei Säuren für vollkommen sicher und theilt in dieser Beziehung noch folgende Tabelle mit.

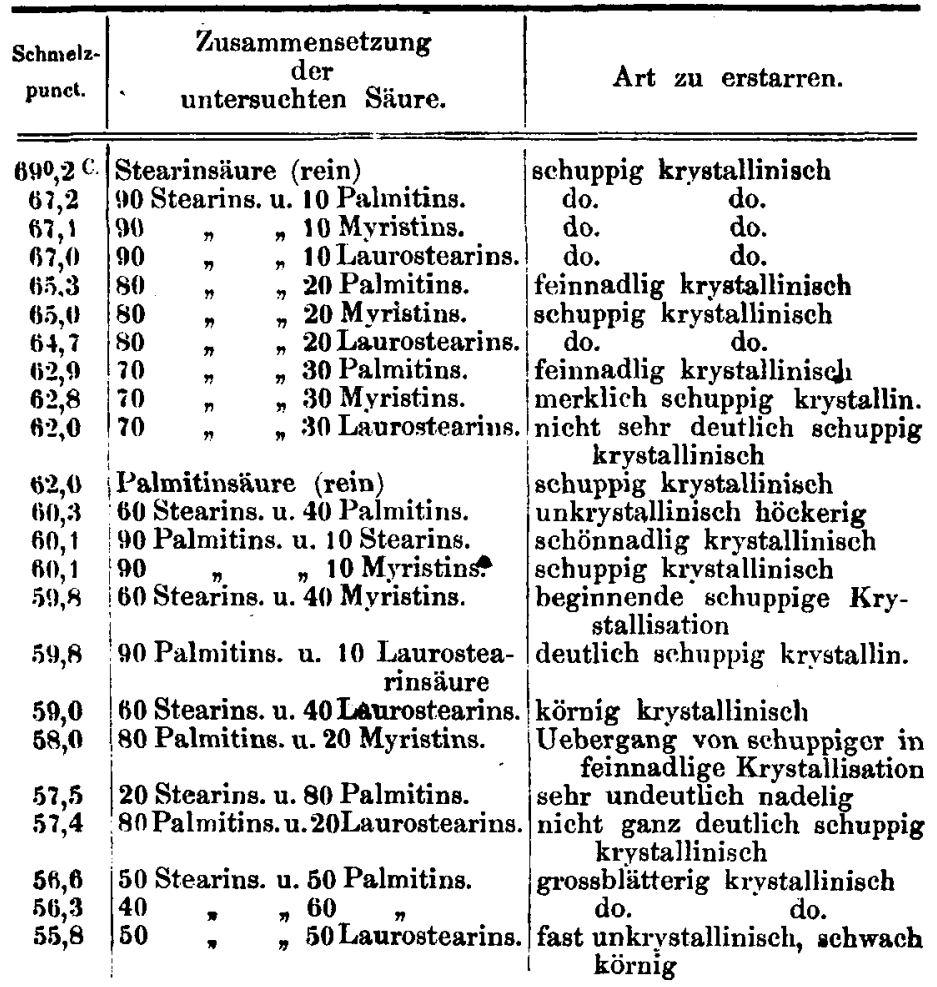




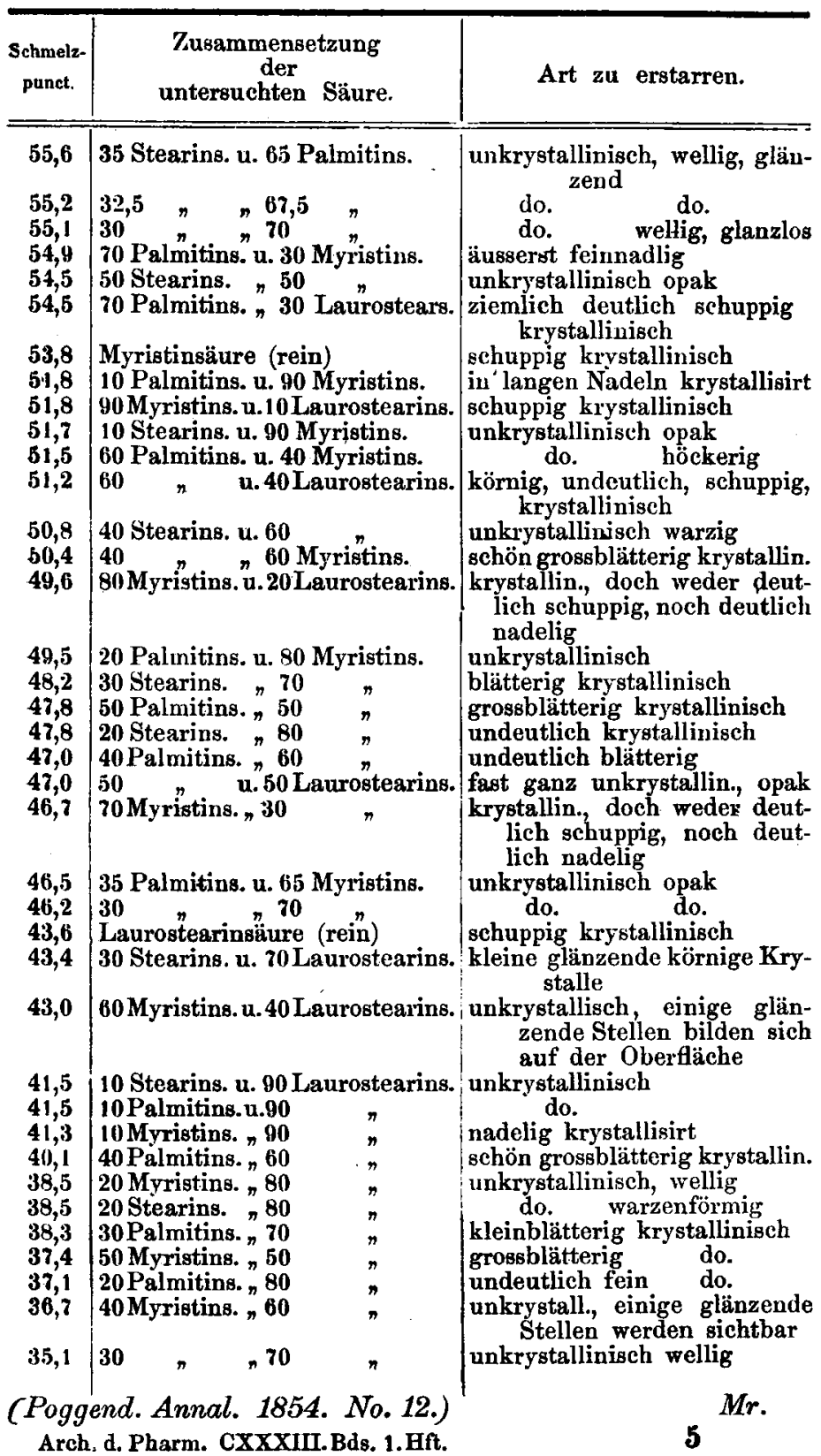

